Kiryoku, Volume 3 No 12019

e-ISSN: 2581-0960 p-ISSN: 2599-0497

Tersedia online di http://ejournal.undip.ac.id/index.php/kiryoku

\title{
SUFIKS PEMBENTUK VERBA TRANSITIF DAN INTRANSITIF DALAM BAHASA JEPANG
}

\author{
Lina Rosliana*, Novy Prasilia Yunadi \\ Universitas Diponegoro \\ *Email: lina.rosliana@live.undip.ac.id
}

\begin{abstract}
Abstrak
Penelitian ini bertujuan untuk menjelaskan proses pembentukan verba dari sufiks pembentuk verba transitif dan intransitif. Data pada penelitian ini diambil dari website Asahi Shinbun, More Zasshi, News Livedoor dan berbagai website Jepang lainnya. Metode yang digunakan dalam penelitian ini adalah metode deskriptif, dan metode analisis datanya dengan metode agih. Teori yang digunakan dalam penelitian ini adalah teori verba, derivasi dan sufiks pembentuk verba. Hasil penelitian menunjukan bahwa (1) Ada 5 jenis sufiks pembentuk verba yaitu sufiks -garu,-maru, -meru, -mu, dan -suru, (2) Sufiks -garu dapat melekat pada adjektiva-i, adjektiva- na dan bentuk - tai yang dapat menghasilkan verba transitif maupun intransitif (3) Sufiks -maru dapat melekat pada adjektiva-I yang menghasilkan verba intransitif (4) Sufiks -meru dapat melekat pada adjektiva-i yang menghasilkan verba transitif (5) Sufiks -mu dapat melekat pada adjektiva-i yang dapat menghasilkan verba transitif maupun intransitif (6) Sufiks -suru dapat melekat pada nomina dan adverbia yang dapat menghasilkan verba transitif maupun intransitif (7) Masing-masing sufiks pembentuk verba ada yang merubah makna kata asalnya dan ada yang tidak merubah makna namun penggunaannya saja.
\end{abstract}

Kata kunci: sufiks; verba transitif; verba intransitif

\begin{abstract}
(Title: Suffix Formers of Transitive And Intransitive Verbs In Japanese Language) This research aims to explain the process of formation verbs from the suffix of transitive and intransitive verb formers and their meanings. The data in this research were taken from Asahi Shinbun website, More Zasshi, News Livedoor and various other Japanese websites. The method which used in this research is descriptive method, and for data analysis using agih method. The theory which used in this research are verb, derivation and verb-forming suffix theory. The results of the research show that (1) There are 5 types of verb-forming suffixes: suffix -garu,-maru, -meru, -mu, and -suru, (2) Suffix -garu can be attached to adjective-i, adjective-na and -tai forms that can produce transitive and intransitive verbs (3) Suffix-maru can be attached to adjective-i and produce the intransitive verb (4) Suffix -meru can be attached to adjective-i and produce the transitive verb (5) Suffix -mu can be attached to adjective-i which can produce transitive and intransitive verbs (6) Suffix -suru can be attached to nouns and adverbs that can produce transitive or intransitive verbs (7) Some of verb-forming suffix can changes the meaning of the original word and some just changes the application.
\end{abstract}

Keywords : Suffix; transitive verb; intransitive verb 


\section{PENDAHULUAN}

Dalam proses pembentukan kata dalam bahasa Jepang ada yang disebut dengan derivasi/turunan. Kata yang dihasilkan dari cara derivasi disebut haseigo ( 派生 語). Haseigo adalah gabungan kata dengan imbuhan/afiks. Imbuhan dapat berupa awalan/prefiks (settouji/ 接頭辞) atau akhiran/sufiks (setsubijil 接尾辞) (Akimoto, 2002:92). Jenis-jenis sufiks ada beragam salah satunya adalah sufiks pembentuk verba. Penambahan sufiks pada kelas kata verba dapat membentuk kata turunan verba transitif maupun intransitif dari bentuk dasar kelas kata nomina, adjektiva ataupun adverbia.

Seperti salah satu contoh di bawah ini, yaitu pembentukan verba dari kelas kata adjektiva:

\begin{tabular}{|c|c|c|}
\hline Atsu (i) & -meru & atsumeru \\
\hline Panas & & memanaskan \\
\hline Adjektiva-i & & Verba Transitif \\
\hline (2) 暑 (ઐ) + & 一がる & ＼cjkstart暑がる \\
\hline Atsu (i) & -garu & atsugaru \\
\hline Panas & & menjadi panas \\
\hline
\end{tabular}

\section{Adjektiva-i Verba Intransitif}

Dilihat dari contoh di atas, melalui proses sufiksasi atau proses pembubuhan sufiks yang berbeda pada bentuk dasar sebuah kata yang sama dapat menghasilkan kata turunan verba yang berbeda, yaitu verba transitif atau intransitif dan memberikan penambahan makna yang berbeda pula. Perlu diketahui tidak semua kata turunan verba transitif dibentuk dari sufiks -meru, begitu juga dengan kata turunan verba intransitif tidak selalu dibentuk dari sufiks -garu. Selain itu pembubuhan sufiks juga tidak selalu memberikan penambahan makna pada kata yang dibubuhinya.

Sulitnya membedakan apa saja sufiks pembentuk kata turunan verba transitif dan intransitif serta makna yang dihasilkannya, terkadang membuat pengguna bahasa Jepang merasa kebingungan ketika menggunakannya. Penelitian ini akan membahas bagaimana sufiks dalam bahasa Jepang dapat membentuk verba transitif dan intransitif. Pada penelitian ini peneliti membatasi pada kajian morfologi yaitu, proses pembentukan kata turunan verba transitif dan intransitif dari sufiks -garu, -maru, meru, -mu dan -suru, karena sufiks-sufiks tersebut adalah sufiks yang jelas dapat merubah kelas kata adjektiva, nomina serta adverbia ke bentuk verba, baik transitif maupun intransitif.

Penelitian sejenis telah dilakukan sebelumnya, misalnya penelitian dari Hayatinufus (2004) dan Ardiansyah (2013) yang membahas tentang sufiks garu, mu, maru, dan meru sebagai pembentuk verba de adjektival dalam bahasa Jepang, namun, penelitianpeneltian di atas hanya membahas sufiks pembentuk verba yang melekat pada kelas kata adjektiva, sedangkan pada penelitian ini, peneliti akan memaparkan sufiks pembentuk verba transitif dan intransitif yang melekat pada kelas kata adjektiva dan kelas kata yang lain.

\section{METODE}

Metode adalah cara yang harus dilaksanakan atau diterapkan, teknik adalah cara melaksanakan atau menerapkan metode (Sudaryanto, 2015: 9). Penulis menggunakan metode penelitian deskriptif karena penelitian ini mempunyai tujuan untuk menemukan pola-pola pembentukan, kaidah-kaidah yang bersifat mengatur di dalam bahasa itu, menemukan sistem (sistem fonotaksis, sistem fonologi, 
sistem morfologi, sistem penjenisan kata, sistem fraseologi, sistem pembentukan kalimat, sistem pengaturan informasi di dalam wacana dan sistem semantik) (Subroto, 1992: 9).

Peneliti menggunakan metode kualitatif yang banyak dipakai untuk ilmuilmu kebudayaan atau ilmu-ilmu humaniora. Secara umum metode kualitatif adalah metode pengkajian atau metode penelitian terhadap suatu masalah yang tidak didesain atau dirancang menggunakan prosedur-prosedur statistik. Karena bersifat deskriptif, peneliti mencatat dengan teliti dan cermat data yang berwujud kata-kata, kalimat-kalimat, wacana, gambar, foto, catatan harian, memorandum, video tape (Subroto, 1992: 4-7).

Teknik pengumpulan data sangat diperlukan dalam suatu penelitian karena hal tersebut digunakan penulis untuk mendapatkan data yang akan diolah sehingga bisa ditarik kesimpulan. Teknik yang digunakan adalah teknik pustaka, yang dimaksud dengan teknik pustaka di sini adalah mempergunakan sumbersumber tertulis untuk memperoleh data. Sumber-sumber tertulis yang digunakan dipilih yang mencerminkan sinkronis. Sumber tertulis itu dapat berwujud majalah, surat kabar, karya sastra, buku bacaan umum, karya ilmiah, buku perundang undangan (Subroto, 1992:42).

Data pada penelitian ini bersumber dari Asahi Shinbun, More Zasshi, Livedoor News dan lain - lain. Penulis membaca dan memilah data - data yang mengandung topik dari penelitian. Setelah mendapatkannya, data - data tersebut diambil untuk dianalisis dengan mencantumkan sumbernya.

Sesuai dengan namanya "analisis", tahap ini merupakan upaya sang peneliti menangani langsung masalah yang terkandung pada data (Sudaryanto, 2015:7). Analisis data merupakan langkah yang terpenting dalam suatu penelitian.
Data yang telah diperoleh akan dianalisis pada tahap ini sehingga dapat ditarik kesimpulan.

Metode yang tepat untuk penelitian ini adalah metode agih, yaitu metode analisis yang alat penentunya justru bagian dari bahasa yang bersangkutan itu sendiri (Sudaryanto, 2015:18). Dengan menggunakan teknik dasarnya, yaitu teknik bagi unsur langsung dan teknik lanjutannya yaitu teknik perluas yang kegunaannya untuk menentukan segi-segi kemaknaan (aspek semantis) satuan lingual tertentu (Sudaryanto, 2015:69).

Sesuai pula dengan namanya "penyajian", tahap ini merupakan upaya sang peneliti menampilkan dalam wujud "laporan" tertulis akan apa-apa yang telah dihasilkan dari kinerja analisis, khususnya kaidah (Sudaryanto, 2015:8). Hasil analisis yang berupa kaidah-kaidah dapat disajikan melalui dua cara, yaitu yang bersifat informal dan yang bersifat formal. Metode penyajian informal adalah perumusan dengan kata-kata biasa, walaupun dengan terminologi yang teknis sifatnya; sedangkan penyajian formal adalah perumusan dengan apa yang umum dikenal sebagai tanda atau lambanglambang (Sudaryanto, 2015: 240-241). Oleh karena itu metode yang tepat untuk penyajian hasil analisis data pada penelitian ini adalah metode informal dengan menggunakan kata-kata biasa.

\section{HASIL DAN PEMBAHASAN}

\section{Klasifikasi Sufiks}

Menurut Akimoto (2002:93) sufiks atau setsubiji dapat diklasifikasikan berdasarkan jenis kelas kata dan maknanya, yaitu:

1. Meishisei setsubiji (sufiks yang membentuk nomina).

Contoh: $-s a+$ omoi (berat) $\rightarrow$ omosa (beratnya)

2. Doushisei setsubiji (sufiks yang membentuk verba). 
Kiryoku, Volume 3 No 12019

e-ISSN: 2581-0960 p-ISSN: 2599-0497

Tersedia online di http://ejournal.undip.ac.id/index.php/kiryoku

Contoh: -garu + hoshi (mau) $\rightarrow$ hoshigaru (menginginkan)

3. Keiyoushisei setsubiji (sufiks yang membentuk adjektiva-i).

Contoh: -ppoi + kodomo (anak) $\rightarrow$ kodomoppoi (seperti anak kecil)

4. Keiyoudoushisei setsubiji (sufiks yang membentuk adjektiva-na).

Contoh: -teki + doutoku (moral) $\rightarrow$ doutokuteki (etika, moral)

5. Fukushisei setsubiji (sufiks yang membentuk adverbia).

Contoh:-jo + tachiba (kedudukan) $\rightarrow$ tachibajo (dari segi kedudukan)

\section{Sufiks Pembentuk Verba}

Pembentukan kata turunan verba dapat dilakukan dengan cara melekatkan sufiks atau akhiran pada sebuah kata atau disebut sufiksasi, yang dapat mengubah makna kata ataupun jenis kata (Sunarni, 2010:52). Terdapat banyak sufiks yang dapat membentuk kata turunan verba, seperti sufiks -garu, -meru,-maru,-mu, dan -suru.

\section{A. Sufiks -garu}

Sufiks -garu menunjukkan sifat/ kecenderungan dari pihak ke tiga (Sunarni, 2010:52). Akhiran -garu digunakan untuk membentuk verba dari adjektiva bahasa Jepang. Pembentukan verba dengan akhiran -garu dilakukan dengan membubuhkan akhiran -garu setelah menghapus akhiran $-i$ atau $-n a$ pada adjektiva yang dilekatinya. Contoh : hazukashii+-garu $\rightarrow$ hazukashigaru dan iyana+-garu $\rightarrow$ iyagaru.

Penambahan sufiks -garu pada adjektiva dapat membentuk verba turunan transitif maupun intransitif. Pada pembentukan verba transitif hampir tidak mengubah makna kata asalnya tetapi mengubah penggunaan katanya yang hanya terbatas untuk orang diluar pembicara. Sehingga sufiks -garu disini seperti menambahkan makna 'sepertinya' atau 'terlihat'. Namun pada pembentukan verba intransitif terdapat perubahan makna. Sufiks -garu yang dilekatkan pada adjektiva tersebut seperti mengandung makna 'seolah-olah' (Caniago, 2013:71).

Selain itu, sufiks - garu juga dapat dilekatkan dengan bentuk keinginan - tai. Proses pembentukannya dengan menghilangkan akhiran $-i$ pada bentuk tai kemudian menambahkan sufiks -garu. Biasanya bentuk tersebut digunakan untuk orang kedua atau ketiga (diluar si pembicara) dengan makna 'cenderung ingin'

(Sunarni, 2010:53). Contoh: kekkonshitai+-garu $\rightarrow$ kekkonshitagaru .

Sufiks - garu juga dapat diubah ke dalam bentuk -teiru menjadi -gatteiru yang menerangkan bahwa hal tersebut hanya terjadi di waktu tertentu tidak berulang atau terus menerus. Berikut adalah contoh analisisnya.

(1.1) 私歯茎出るくらい全力で笑ってる からちょっと恥ずかしい笑。

Watashi/ haguki/ deru/ kurai/ zenryoku/ del waratteru/ kara/ chotto/ hazukashiil warai.

Saya/ gusi/ keluar/ kira-kira/ sekuat tenaga/ partikel/ tertawa/ karena/ sedikit/ $\underline{\text { malu/ tertawa. }}$

'Saya sedikit malu ketika sedang tertawa karena gusi saya terlihat sedikit keluar.'

(more.hpplus.jp)

Pembentukan hazukashigaru adalah dengan menghilangkan gobi (akhiran) -i pada Adjektiva-i hazukashii, menjadi hazukashi lalu melekatkan sufiks -garu setelah gokon dan menghasilkan sebuah kata turunan yaitu hazukashigaru yang kelas katanya berubah menjadi verba transitif. 
Kiryoku, Volume 3 No 12019

e-ISSN: 2581-0960 p-ISSN: 2599-0497

Tersedia online di http://ejournal.undip.ac.id/index.php/kiryoku

Hazukashigaru memiliki makna 'merasa malu' yang hampir tidak mengalami perubahan makna dari asal katanya hazukashii, namun digunakan untuk perasaan malu orang lain (diluar pembicara), sehingga sufiks -garu disini mengandung makna 'merasa'.

(1.2) 一生懸命を恥ずかしがるな。

Isshokenmei /wo/ hazukashigaru/na.

Bersungguh-sungguh / partikel/ merasa

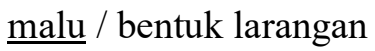

'Jangan merasa malu dengan kerja kerasmu.'

(www. okmusic.jp/news)

Hazukashigaru juga dapat diubah ke bentuk-teiru

menjadi

hazukashigatteiru.

(1.3) 中途半端に恥ずかしがっているの が情けない。

Chuutohanpa/ ni/ hazukashigatteiru/ no/ ga/ nasakenai. Setengah jalan/ partikel/ merasa malu/ partikel/ partikel/ menyedihkan.

'Rasanya menyedihkan saat seseorang merasa malu karena tidak dapat menyelesaikan (pekerjaannya)'

(www.nishinippon.co.jp)

Pembentukan hazukashigatteiru adalah dengan menghilangkan -ru dari hazukashigaru menjadi hazukashiga- lalu melekatkan bentuk -teiru dan menghasilkan hazukashigatteiru dengan makna menunjukkan keadaan 'perasaan malu' untuk orang lain yang muncul sesaat saja di waktu tertentu.

(2.1) 景色を見てるだけで、嫌なことを 全て忘れられた気がしました。
Keshiki/ wo/ miteru/ dake/ de/ iyana/ koto/ wo/ subete/ wasurerareta/ kigashimashita.

Pemandangan/ partikel/ hanya/ partikel/ tidak suka/ hal/ partikel/ semua/ melupakan/ merasa.

'Hanya dengan melihat pemandangan, saya merasa bahwa saya bisa melupakan semua hal buruk.'

(more.hpplus.jp)

Pembentukan iyagaru adalah dengan menghilangkan gobi (akhiran) -na pada adjektiva iya na, menjadi iya lalu melekatkan sufiks -garu setelah gokon dan menghasilkan sebuah kata turunan yaitu iyagaru yang kelas katanya berubah menjadi verba transitif.

Iyagaru memiliki makna 'tidak suka' yang tidak mengalami perubahan makna dari asal katanya iya $n a$, namun penggunaannya yang berbeda. Iyagaru hanya bisa digunakan untuk orang kedua dan ketiga diluar pembicara.

(2.2) 学校に行くのを嫌がった。

Gakkou / ni / iku / no / wo / iyagatta.

Sekolah / partikel / pergi / partikel / partikel / tidak suka.

'Tidak suka berangkat ke sekolah.'

(www.asahi.com)

Iyagaru juga dapat diubah ke bentuk -teiru menjadi iyagatteiru.

(2.3) それを英国が嫌がっている。

Sore/ wo/ eikoku/ga/ iyagatteiru.

Itu/ partikel/ Britania/ partikel/ tidak suka.

'Britania tidak suka itu.'

(www.asahi.com) 
Kiryoku, Volume 3 No 12019

e-ISSN: 2581-0960 p-ISSN: 2599-0497

Tersedia online di http://ejournal.undip.ac.id/index.php/kiryoku

Pembentukan iyagatteiru adalah dengan menghilangkan -ru dari iyagaru menjadi iyaga- lalu melekatkan bentuk teiru dan menghasilkan iyagatteiru dengan makna perasaan 'tidak suka' yang muncul sesaat saja di waktu tertentu.

(3.1) 結婚したくない派も、約半数は 「いつかは結婚したい」と思っている よう。

Kekkonshitakunai/ ha/ mo/ yaku/ hansuu/ ha/ itsuka/ ha/ kekkonshitai/ to/ omotteiru/ you.

Tidak ingin menikah/ kelompok/ juga/ sekitar/ setengah/ partikel/ suatu saat/ partikel/ ingin menikah/ partikel/ berpikir/

'Sekitar setengah dari mereka yang tidak ingin menikah pun tampaknya berpikiran [aku ingin menikah suatu saat nanti]'

(more.hpplus.jp)

Pembentukan kekkonshitagaru adalah dengan menghilangkan gobi (akhiran) -i pada kekkonshitai, menjadi kekkonshita lalu melekatkan sufiks -garu setelahnya dan menghasilkan sebuah kata turunan yaitu kekkonshitagaru yang merupakan verba intransitif.

Kekkonshitagaru memiliki makna 'ingin menikah' yang hampir tidak mengalami perubahan makna dari asal katanya kekkonshitai, namun penggunaannya yang berbeda. Kekkonshitagaru hanya bisa digunakan untuk orang kedua dan ketiga diluar pembicara, mengandung kesan cenderung ingin menikah dengan wanita Jepang sesuai deskripsi kalimat berikut.

(3.2) [優しくて賢いから] と日本の女性 と結婚したがる中国の男がいっぱいだ よね」
Yasasikute/ kashikoi/ kara/ to/ nihon/ no/ josei/ to/ kekkonshitagaru/ chuugoku/ no/otoko/ga/ ippai/ dayo/ ne.

Baik hati/ cerdas/ karena/ partikel/ Jepang/ partikel/ wanita/ partikel/ ingin menikah/ negara Cina/ partikel /pria/ partikel / banyak/ partikel / partikel.

'Banyak pria Cina yang ingin menikahi wanita Jepang [karena baik dan pintar]'

(news.livedoor.com)

Kekkonshitagaru juga dapat diubah ke bentuk-teiru menjadi

kekkonshitagatteiru.

(3.3) 最近、男子こそ結婚したがってい るんです!

Saikin/ danshil koso/ kekkonshitagatteirun/desu.

Akhir-akhir ini/ laki-laki/ partikel/ ingin menikah/ kopula.

'Akhir-akhir ini, lelakilah yang ingin menikah!'

(more.hpplus.jp)

Pembentukan kekkonshitagatteiru adalah dengan menghilangkan $-r u$ dari kekkonshitagaru menjadi kekkonshitagalalu melekatkan bentuk -teiru dan menghasilkan kekkonshitagatteiru dengan makna 'ingin menikah' yang muncul sesaat saja di waktu tertentu.

\section{B. Sufiks -maru}

Menurut Iori (2000:42) sufiks maru apabila dilekatkan pada pangkal kata/gokan i-keiyoushi akan membentuk verba intransitif dengan arti $一$ くる atau 'menjadi'. Contoh: yowai+maru $\rightarrow$ yowamaru. Berikut adalah contoh analisisnya.

(1. 1)私はこころが弱いんです。

Watashi/ha/ kokoro/ga/yowain/desu. 
Kiryoku, Volume 3 No 12019

e-ISSN: 2581-0960 p-ISSN: 2599-0497

Tersedia online di http://ejournal.undip.ac.id/index.php/kiryoku

Saya/ partikel/ hati/ partikel/ lemah/ kopula

'Hati saya lemah.'

(www.asahi.com)

Pembentukan yowamaru adalah dengan menghilangkan gobi (akhiran) $-\mathrm{i}$ pada Adjektiva-i yowai, menjadi yowa lalu melekatkan sufiks -maru setelah gokon dan menghasilkan sebuah kata turunan yaitu yowamaru yang kelas katanya berubah menjadi verba intransitif.

Yowamaru memiliki makna 'mereda atau melemah' yang mengalami perubahan makna dari asal katanya yowai.

(1.2) 14 日は冬型の気圧配置が緩み、 雪は弱まる見通しだ。

14 hi/ ha/ fuyu/gata/ no/ kiatsuhaichi/ ga/ yurumi/ yuki/ ha/ yowamaru/ mitooshida.

Tanggal 14/ partikel/ salju/ pola/ partikel/pola tekanan/ partikel/ kelonggaran/ salju/ partikel/ mereda/ memperkirakan.

'Pada tanggal 14 pola tekanan musim dingin menurun, salju pun diperkirakan mereda.'

(www.asahi.com)

（2.1）悩みは深い。

Nayami /hal fukai.

Masalah/ partikel/ dalam.

'Masalahnya dalam.'

(www.asahi.com)

Pembentukan fukamaru adalah dengan menghilangkan gobi (akhiran) -i pada adjektiva-i fukai, menjadi fuka lalu melekatkan sufiks -maru setelah gokon dan menghasilkan sebuah kata turunan yaitu fukamaru yang kelas katanya berubah menjadi verba intransitif. Fukamaru memiliki makna 'mendalam' yang mengalami perubahan makna dari asal katanya fukai.

（2.2）日韓関係も、今後もつと深まる と思う。

Nikkan/ kankei/ mo/ kongo/ motto/ fukamaru/ to/ omou.

Jepang Korea/ hubungan/ juga/ kedepannya/ lebih/ mendalam / partikel/ saya pikir.

'Saya pikir hubungan antara Jepang dan Korea akan semakin mendalam kedepannya.'

(www.asahi.com)

\section{Sufiks -meru}

Menurut Iori (2000:42) sufiks meru apabila dilekatkan pada pangkal kata/gokan i-keiyoushi akan membentuk verba transitif dengan arti 一くする. Contoh: katai+-meru $\rightarrow$ katameru. Berikut adalah contoh analisisnya.

(1.1) 最後は固い握手で 40 年ぶりの対 決を締めくくった。

Saigo/ ha/ katai/ akushu/ del 40 nen/ buri/ no/ taiketsu/wo/shimekukutta

Terakhir/ partikel/ keras/ jabat tangan/ partikel/ 40 tahun/ setelah beberapa waktu/ partikel/ pertikaian/ partikel/ mengakhiri. 'Pada akhirnya saya mengakhiri pertikaian selama 40 tahun dengan jabat tangan yang keras.'

(news.livedoor.com)

Pembentukan katameru adalah dengan menghilangkan gobi (akhiran) -i pada Adjektiva-i katai, menjadi kata lalu melekatkan sufiks -meru setelah gokon dan menghasilkan sebuah kata turunan yaitu katameru yang kelas katanya 
Kiryoku, Volume 3 No 12019

e-ISSN: 2581-0960 p-ISSN: 2599-0497

Tersedia online di http://ejournal.undip.ac.id/index.php/kiryoku

berubah menjadi verba transitif. Katameru memiliki makna 'mengeraskan' yang mengalami perubahan makna dari asal katanya katai.

(1.2) スプレーで固めるのも好きじゃな いんです。

Supereel del katameru/ no/ mol sukijanain/desu.

Semprotan/ partikel/ mengeraskan/ partikel/ juga/ kurang suka/ kopula.

'Saya juga kurang suka mengeraskan rambut dengan semprotan (spray).'

(more.hpplus.jp)

\section{Sufiks $-m u$}

Sufiks $-m u$ menurut Caniago (2013:72) hanya dapat ditambahkan pada sedikit adjektiva, yaitu adjektiva yang menyatakan perasaan (kanjou keiyoushi) saja. Contoh: kurushii+-mu $\rightarrow$ kurushimu. Berikut adalah contoh analisisnya.

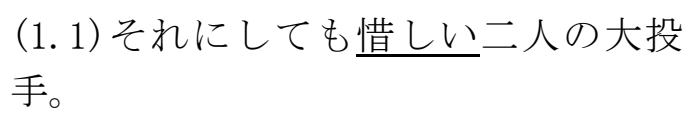

Sorenishitemo/ oshiil futari/ no/ dail toushu.

Namun/ sayang / berdua/ partikel/ hebat/ pelempar.

'Namun sayang mereka berdua adalah pelempar yang hebat.'

(www.asahi.com)

Pembentukan oshimu adalah dengan menghilangkan gobi (akhiran) -i pada Adjektiva-i oshii, menjadi oshi lalu melekatkan sufiks -mu setelah gokon dan menghasilkan sebuah kata turunan yaitu oshimu yang kelas katanya berubah menjadi verba transitif. Oshimu memiliki makna 'menyesali' yang mengalami perubahan makna dari asal katanya oshii.
（1.2）努力を惜しむな。

Doryoku /wo/ oshimu/na.

Usaha / partikel/ menyesali / bentuk larangan

'Jangan menyesali usahamu.'

(www.asahi.com)

\section{E. Sufiks -suru}

Sufiks -suru menurut Akimoto (2002:94) dapat membentuk kata turunan verba dari kelas kata nomina dan adverbia. Didukung oleh pernyataan Nitta (2003:99) yang menerangkan bahwa verba -suru dapat terbentuk dari nomina kata serapan, nomina yang ditulis dalam huruf kanji serta adverbia seperti tiruan bunyi benda mati maupun benda hidup, tiruan bunyi gerakan, keadaan dan menggambarkan perasaan manusia. Pembentukan verba suru dari nomina mengekspresikan „gerakan" dan pembentukan verba -suru dari adverbia mengekspresikan 'menjadi'. Contoh: hirune+-suru $\rightarrow$ hirune suru dan mushakusha+-suru $\rightarrow$ mushakusha. Berikut adalah contoh analisisnya.

(1.1) OPPO では、中国の昼寝の習慣に 合わせて、昼休夕は 2 時間取れるそう です。

OPPO/ del hal Chugoku/ no/ hirune/ no/ shuukan/ ni/ awasete/ hiruyasumi/ ha/ 2 jikan/toreru/sou/desu .

OPPO/ partikel/ partikel/ Cina/ partikel/ tidur siang/ partikel/ kebiasaan/ partikel/ selain/ istirahat siang/ partikel/ $2 \mathrm{jam} /$ mengambil/ sepertinya/ kopula .

'Di perusahaan OPPO dapat mengambil istirahat siang selama 2 jam, mengikuti kebiasaan tidur siang di Cina.'

(news.livedoor.com) 
Kiryoku, Volume 3 No 12019

e-ISSN: 2581-0960 p-ISSN: 2599-0497

Tersedia online di http://ejournal.undip.ac.id/index.php/kiryoku

Pembentukan hirunesuru adalah dengan melekatkan sufiks -suru setelah gokon dan menghasilkan sebuah kata turunan yaitu hirunesuru yang kelas katanya berubah menjadi verba intransitif. Hirunesuru memiliki makna 'tidur siang' yang tidak mengalami perubahan makna dari asal katanya hirune.

$$
\text { ) ソファでお昼寝する太郎。 }
$$

Sofal del ohirunesuru/ Taro.

Sofa/ partikel/ tidur siang/ Taro.

'Taro tidur siang di Sofa.'

(more.hpplus.jp)

Hirunesuru juga dapat diubah ke bentuk teiru menjadi hiruneshiteiru.

(1.3) どちらも夜になると狩りを始める ので、日中は木の上で昼寝しているこ とが多いみたいですね。

Dochiral mo/ yoru/ ni/ naru/ to/ kari/ hajimeru/ node/ nicchuu/ ha/ ki/ no/ uel del hiruneshiteiru/ kotogal ooil mitail desu/ne.

Keduanya/ juga/ malam hari/ partikel/ menjadi/ partikel/ berburu/ memulai/ karena/ siang hari/ partikel/ pohon/ partikel/ atas/ partikel/ tidur siang/ hal/ partikel/ banyak/ seperti/ kopula/ partikel.

'Keduanya mulai berburu di malam hari, jadi sepertinya mereka sering tidur siang di pohon pada siang hari.'

(news.livedoor.com)

Pembentukan hiruneshiteiru adalah dengan mengubah -suru ke dalam bentuk -teiru menjadi hiruneshiteiru yang maknanya tidak berubah namun -teiru disini mengandung arti sedang dilakukan atau sedang terjadi.
(2.1) それで日頃のむしやくしゃやスト レスが解消され、犯罪が減るのかもし れませんね。

Soredel higorol no/ mushakushal yal sutoresu/ ga/ kaishousarel hanzail gal heru/no/kamoshirimasen/ne .

Lalu/ biasanya/ partikel/ jengkel/ dan/ stress/ partikel/ pembubaran/ kejahatan/ partikel/ menurun/ mungkin/ partikel.

'Biasanya dengan menghilangkan hal yang membuat jengkel dan stress dapat menurunkan tingkat kejahatan.'

(news.livedoor.com)

Pembentukan mushakushasuru adalah dengan melekatkan sufiks -suru setelah gokon dan menghasilkan sebuah kata turunan yaitu mushakushasuru yang kelas katanya berubah menjadi verba intransitif. Mushakushasuru memiliki makna 'menjadi jengkel' yang hampir tidak mengalami perubahan makna dari asal katanya mushakusha.

(2.2) でもアルコールに依存している人 は、さしゃくしゃするから飲むんです よ。

Demo/ arucooru/ ni/ izonshiteiru/ hito/ ha/ mushakushasuru/kara/ nomun/desu/yo.

Tetapi/alkohol/

partikel/

ketergantungan/orang/ partikel/ menjadi jengkel/ kara/ minum/ kopula/ partikel.

'Karena menjadi jengkel orang-orang yang ketergantungan alkohol akan minum.'

(news.livedoor.com)

Mushakushasuru juga dapat diubah ke bentuk-teiru menjadi mushakushashiteiru.

(2.3) ギャンブルで負けて导しゃくしゃ していた。 
Kiryoku, Volume 3 No 12019

e-ISSN: 2581-0960 p-ISSN: 2599-0497

Tersedia online di http://ejournal.undip.ac.id/index.php/kiryoku

Gyanburu/ de/makete/ mushakushashiteita. Berjudi/ partikel/ kalah/ menjadi jengkel.

'Menjadi jengkel karena kalah berjudi.'

(www.asahi.com)

Pembentukan mushakushashiteiru adalah dengan mengubah -suru ke dalam bentuk -teiru menjadi mushakushashiteiru yang maknanya tidak berubah namun teiru disini mengandung arti sedang dilakukan atau sedang terjadi.

\section{SIMPULAN}

Berdasarkan pemaparan hasil dan pembahasan sebelumnya, dapat diambil kesimpulan bahwa terdapat 5 jenis sufiks pembentuk verba yaitu sufiks -garu, maru, -meru, -mu dan -suru. Dalam proses pembentukan verba yang berasal dari adjektiva, dilakukan dengan menghilangkan gobi/akhiran -i pada adjektiva-i atau menghilangkan gobi/akhiran -na pada adjektiva-na lalu melekatkan sufiks pembentuk verba setelah gokon. Untuk pembentukan verba yang berasal dari nomina dan adverbia dilakukan dengan melekatkan sufiks pembentuk verba setelah gokon. Berikut rincian karakteristik sufiks pembentuk verba dan makna yang dihasilkan:

1. Sufiks-garu

a) Melekat pada adjektiva-i, adjektiva-na dan bentuk-tai.

b) Melekat pada adjektiva yang menyatakan penilaian, ukuran dan perasaan.

c) Pembubuhan sufiks pada adjektiva yang menyatakan perasaan akan menghasilkan verba transitif yang tidak mengalami perubahan makna dari kata dasarnya, namun penggunaannya. d) Pembubuhan sufiks pada adjektiva yang menyatakan penilaian dan ukuran akan menghasilkan verba intransitif yang dapat merubah makna kata dasarnya.

e) Pembubuhan sufiks pada bentuk -tai dapat menghasilkan verba transitif maupun intransitif yang tidak mengalami perubahan makna dari kata dasarnya, namun penggunaannya saja yang berbeda.

2. Sufiks - maru

a) Melekat pada adjektiva-i.

b) Melekat pada adjektiva yang menyatakan penilaian dan ukuran.

c) Menghasilkan verba intransitif yang dapat merubah makna kata dasarnya.

3. Sufiks -meru

a) Melekat pada adjektiva-i.

b) Melekat pada adjektiva yang menyatakan penilaian dan ukuran.

c) Menghasilkan verba transitif yang dapat merubah makna kata dasarnya.

4. Sufiks $-m u$

a) Melekat pada adjektiva-i.

b) Melekat pada adjektiva yang menyatakan perasaan.

c) Umumnya menghasilkan verba transitif namun ada beberapa adjektiva yang dapat menghasilkan verba transitif maupun intransitif tergantung penggunaannya dalam kalimat.

d) Pembubuhan sufiks ada yang dapat merubah makna dan ada yang tidak mengubah makna, namun penggunaannya saja yang berbeda. 
5. Sufiks -suru

a) Melekat pada nomina dan adverbia.

b) Pembubuhan sufiks pada nomina dapat menghasilkan verba transitif maupun intransitif.

c) Pembubuhan sufiks pada nomina ada yang dapat merubah makna dan ada yang tidak mengubah makna.

Pembubuhan sufiks pada adverbia hanya dapat menghasilkan verba intransitif yang tidak mengalami perubahan makna dari kata dasarnya.

\section{DAFTAR PUSTAKA}

Akimoto, Miharu. (2001). Yoku Wakaru Goi. Japan: ARK Corporation.

Caniago, Ardiansyah. (2013). Analisis Pembentukan Nomina dan Verba yang Berasal dari Adjektiva-I Bahasa Jepang (Skripsi). Medan: Universitas Sumatera Utara.

Hayatinufus. (2004). Sufiks -maru, -meru, -mu Sebagai Pembentuk Verba De

Adjektival dalam Bahasa Jepang (Skripsi). Bandung: Universitas

Padjajaran.

Iori, Isao, et al. (2000). Nihongo Bunpou Handobukku. Tokyo: 3A Corporation.

Koizumi, Tomatsu. (1993). Nihongo Kyoushi no Tame Gengogaku Nyuumon. Tokyo : Taishuukan Shoten.

Kridalaksana, Harimurti. (2008). Kamus Linguistik. Jakarta: Gramedia Pustaka Utama.

Machida, Ken. (1995). Yoku Wakaru Gengogaku Nyuumon. Tokyo: Babel Press.

Nitta. (2003). Gendai Nihon Go Bunpou 1.Tokyo: Kuroshio Shuppan.

\section{Rujukan Elektronik:}

more.hpplus.jp

news.livedoor.com

www.asahi.com 